\title{
Experimental Study of the Physical and Mechanical Properties of Recycled Aggregate Pervious Concrete
}

\author{
Yangang Zhang ${ }^{1, a}$, Yunxing Shi ${ }^{1, b}$, Kun Ni ${ }^{1, c}$, Fasheng Zhang ${ }^{1, d}$ \\ ${ }^{1}$ Technical Center, China State Construction Engineering Co. LTD.

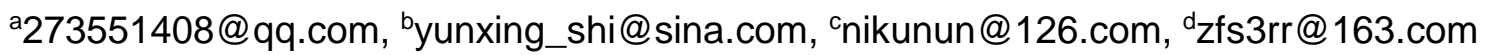

\begin{abstract}
Keywords: recycled aggregate pervious concrete, mix design, water cement ratio, aggregate binder ratio

Abstract. Mix design of recycled aggregate pervious concrete for construction is introduced. The effects of aggregate binder ratio and water cement ratio on the compressive strength and flexural strength of recycled aggregate pervious concrete were studied, The result shows that the compressive strength of the pervious concrete increases with the decrease of aggregate binder ratio when water cement ratio is 0.275 , whereas the flexural strength initially increases and subsequently plateaus . When the aggregate binder ratio is 4 , as water cement ratio increases, the compressive strength of the pervious concrete initially increases and subsequently decreases while the flexural strength decreases.
\end{abstract}

\section{Introduction}

With the development of the national infrastructure as well as the retrofits of a large area of existing buildings, waste concrete is gradually increasing. Waste concrete not only results in dust pollution, but also reduces the urban space and aggravates the urban environment. Statistically, the quantity of waste concrete discarded in China is approximately $5.4 \times 108$ t every year, however, the utilization ratio of recycled waste concrete (less than 5\%) is far lower than that in the United States, Japan and other developed countries (more than 70\%). Consequently, the recycle and effective treatment of construction waste materials have been becoming a key issue.

As basic raw materials, sand and gravel are non-renewable. Thus their quality is becoming worse and worse with the development of construction industry. In the United States, according to a legislation issued in Oct. 2015, sand and gravel aggregate used in the infrastructure construction and the related minerals were identified as the key strategic resource.

Compared with natural sand and gravel, recycled aggregates have higher air void under the bulk station and thereby can be used for the preparation of pervious concrete. Doing so not only enables the construction waste resource recovery, but also mitigates the lack of natural sand and gravel as well as preserves the non-renewable resources. Recycled aggregate pervious concrete may result in pronounced economic and social benefits and thus has profound significance for the national development.

\section{Main research content}

This paper mainly focuses on the physical and mechanical properties of recycled concrete aggregate (hereinafter referred to as recycled aggregate) pervious concrete. Raw materials selected included cement, recycled aggregate (aggregate size of 5 10mm), silica fume, superplasticizer and water. Experimental protocol include:(1) mix design; (2) Effects of aggregate binder ratio on the compressive strength and the flexural strength of recycled aggregate pervious concrete; (3) Effects of water cement ratio on the compressive strength and the flexural strength of recycled aggregate pervious concrete.

\section{Materials and methods}

\section{Reference standards of testing method}

Four Chinese standards of testing method are referenced in this paper as follows: 
《Standard for technical requirements and test method of sand and crushed stone (or gravel)for ordinary concrete》 (JGJ52-2006);

《Method of testing cements-Determination of strength》(GB/T17671-1999);

《Test methods for water requirement of normal consistency, setting time and soundness of the Portland cement》(GB/T1346-2001);

《Autoclave method for soundness of Portland cement》(GB750-92);

《The test sieving method for fineness of cement》(GB/T1345-2005).

\section{Selection of Materials}

1. Cement: Ordinary Portland cement with the strength grade 42.5 was selected, and its properties are shown in Tab.1.

Tab.1 Physical-mechanical properties of cement

\begin{tabular}{|c|c|c|c|c|c|c|c|c|}
\hline \multirow{2}{*}{$\begin{array}{c}\text { Apparent } \\
\text { density } \\
{\left[\mathrm{g} . \mathrm{cm}^{-3}\right]}\end{array}$} & \multirow{2}{*}{$\begin{array}{c}\text { Fineness } \\
{[\%]}\end{array}$} & \multicolumn{2}{|c|}{ Setting time [min] } & \multicolumn{2}{|c|}{$\begin{array}{c}\text { Flexural strength } \\
{[\mathrm{MPa}]}\end{array}$} & \multicolumn{2}{|c|}{$\begin{array}{c}\text { Compressive strength } \\
{[\mathrm{MPa}]}\end{array}$} & \multirow{2}{*}{ Soundness } \\
\hline & & initial & final & $3 \mathrm{~d}$ & $28 \mathrm{~d}$ & $3 \mathrm{~d}$ & $28 \mathrm{~d}$ & \\
\hline 3.1 & 3.4 & 224 & 297 & 5.9 & 8.8 & 30.6 & 63.4 & qualified \\
\hline
\end{tabular}

Notes: 1 . The water requirement for normal consistency increased is144.5g.

2. The fineness of cement is tested by $0.08 \mathrm{~mm}$ sieve.

2. Recycled aggregate: The range of recycled aggregate size is $5 \sim 10 \mathrm{~mm}$, which is obtained after the old concrete is broken and treated by surface shaping (method: recycled aggregate was put into a self - dropping mixer, and then let the mixer work for 30 minutes to eliminate the edges of recycled aggregate), The physical and mechanical properties of the aggregate are shown in Tab.2, and the morphology of the aggregate is shown in Fig.1.

Tab.2 Physical and mechanical properties of recycled aggregate

\begin{tabular}{|c|c|c|c|c|c|}
\hline $\begin{array}{c}\text { aggregate size } \\
{[\mathrm{mm}]}\end{array}$ & $\begin{array}{c}\text { Apparent } \\
\text { density }\left[\mathrm{kg} \cdot \mathrm{m}^{-3}\right]\end{array}$ & $\begin{array}{c}\text { Bulk density } \\
{\left[\mathrm{kg} \cdot \mathrm{m}^{-3}\right]}\end{array}$ & $\begin{array}{c}\text { Void } \\
\text { fraction[\%] }\end{array}$ & $\begin{array}{c}\text { Water } \\
\text { absorption[\%] }\end{array}$ & $\begin{array}{c}\text { Crushing value } \\
\text { index[\%] }\end{array}$ \\
\hline $5 \sim 10$ & 2234 & 1301 & 41.8 & 4.52 & 12.65 \\
\hline
\end{tabular}

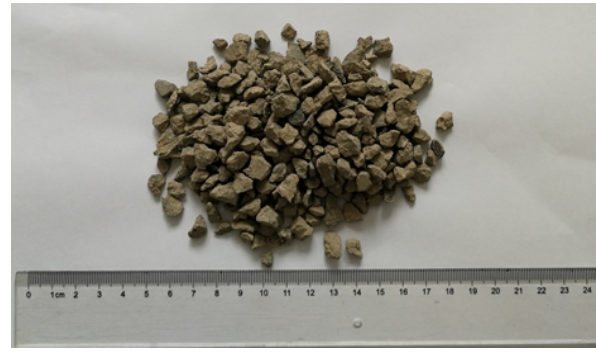

Fig.1 Morphology of recycled aggregate

3. Superplasticizer: Polycarboxylate superplasticizer was selected and its water reducing rate is over $25 \%$.

4. Silica fume: silica fume was used as concrete admixture and its properties are shown in Tab.3. Tab. 3 Characteristics of silica fume

\begin{tabular}{|c|c|c|c|c|}
\hline $\mathrm{SiO}_{2}[\%]$ & Water content[\%] & Loss on ignition[\%] & Total Activity[\%] & Specific surface area[g.m $\left.{ }^{-2}\right]$ \\
\hline 95.1 & 0.4 & 2.9 & 126 & 20 \\
\hline
\end{tabular}

\section{Mix design and concrete preparation}

\section{Mix design}

Pervious concrete should meet the requirements of strength, permeability, cost and workability in real project. Of these parameters, the aggregate binder ratio has a greater influence on the strength and permeability of pervious concrete, and the water cement ratio and superplasticizer have significantly effects on cost and workability of pervious concrete[1.2]. Aimed at the application to the project, the design steps of mix proportion have been determined after many experiments: 


\section{Aggregate volume required}

According to many tests and engineering examples, $1.04 \mathrm{~m}^{3}$ recycled aggregate should be used to prepare $1 \mathrm{~m}^{3}$ pervious concrete.

2. Aggregate binder ratio

The pervious concrete had little porosity and poor water permeability when the aggregate binder ratio is lower than 3.5:1; it had insufficient strength due to excessive porosity when the aggregate binder ratio is greater than 4.5:1. Therefore, the aggregate binder ratios were selected as 3.5:1, 4.0:1 and 4.5:1 to meet the needs of the project[3].

3. Water cement ratio and superplasticizer admixture

The superplasticizer is helpful to improve the strength of the pervious concrete and the workability of the mixture. In practical applications, the admixture of the superplasticizer was selected between $0.9 \%$ and $1.5 \%$.

The optimized dosages of the superplasticizer and the paste liquidity (as shown in Fig.2) under different water cement ratios are shown in Tab.4.

Tab.4 Dosage of superplasticizer and dispersion of binder

\begin{tabular}{|c|c|c|c|}
\hline NO. & Water cement ratio & Superplasticizer [\%] & paste liquidity[mm] \\
\hline 1 & 0.275 & 1.5 & 139 \\
\hline 2 & 0.300 & 1.2 & 138 \\
\hline 3 & 0.325 & 0.9 & 139 \\
\hline
\end{tabular}

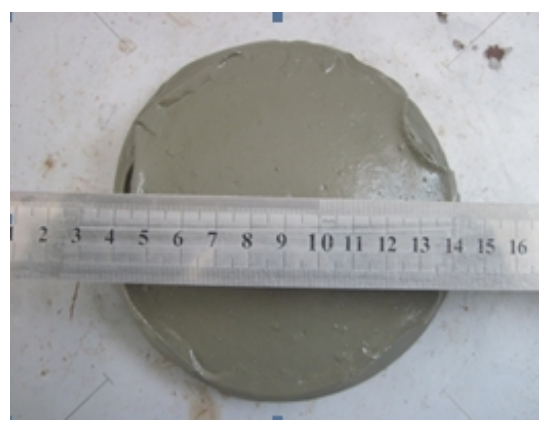

Fig.2 Paste liquidity test

\section{Water content}

Recycled aggregate has relatively high water absorption and has different moisture contents for each batch. Therefor, in the mix design, the water content for different water cement ratios was calculated based on the recycled aggregate under saturated surface drying.

\section{Mix proportion}

The mix proportion of pervious concrete is shown in Tab.5.

Tab.5 Mix proportion of pervious concrete

\begin{tabular}{|c|c|c|c|c|c|c|}
\hline $\begin{array}{c}\text { Type of } \\
\text { aggregate }\end{array}$ & $\begin{array}{c}\text { Mix } \\
\text { proportion }\end{array}$ & $\begin{array}{c}\text { Aggregate } \\
{[\mathrm{kg}]}\end{array}$ & $\begin{array}{c}\text { Cement } \\
{[\mathrm{kg}]}\end{array}$ & $\begin{array}{c}\text { Silica } \\
\text { fume }[\mathrm{kg}]\end{array}$ & $\begin{array}{c}\text { Superplasticizer } \\
{[\mathrm{kg}]}\end{array}$ & $\begin{array}{c}\text { Water } \\
{[\mathrm{kg}]}\end{array}$ \\
\hline \multirow{4}{*}{$\begin{array}{c}\text { Recycled } \\
\text { aggregate }\end{array}$} & $\mathrm{Z}-1$ & 1376 & 328.41 & 9.85 & 5.07 & 130.91 \\
\cline { 2 - 7 } & $\mathrm{Z}-2$ & 1376 & 328.41 & 9.85 & 4.06 & 139.36 \\
\cline { 2 - 8 } & $\mathrm{Z}-3$ & 1376 & 328.41 & 9.85 & 3.04 & 147.82 \\
\cline { 2 - 7 } & Z-4 & 1376 & 375.32 & 11.26 & 5.80 & 144.19 \\
\cline { 2 - 7 } & Z-5 & 1376 & 291.92 & 8.76 & 4.51 & 120.57 \\
\hline
\end{tabular}

\section{Concrete mixing and preparation of specimens}

The prescribed amount of recycled aggregate and 1/3 water were added into a concrete mixer, and the mixture was mixed for 20 seconds. Subsequently, the cement, silica fume, water and superplasticizer were added to the mixture and mixed for additional 120 seconds and the specimens were obtained[3].

For each mix proportion, six cubic specimens with the size of $100 \mathrm{~mm} \times 100 \mathrm{~mm} \times 100 \mathrm{~mm}$ were prepared to measure the compressive strength. Six prismatic specimens with the size of $100 \mathrm{~mm} \times 100$ $\mathrm{mm} \times 400 \mathrm{~mm}$ were prepared to measure the flexural strength. 


\section{Curing}

All the specimens were held for $24 \mathrm{~h}$ and then demoulded. Subsequently, they were cured in standard condition for 28 days to measure the compressive strength and the flexural strength[4].

\section{Results and discussion}

\section{The effects of the aggregate binder ratio on the compressive strength}

The relationship between compressive strength and aggregate binder ratio are shown in Fig.3.

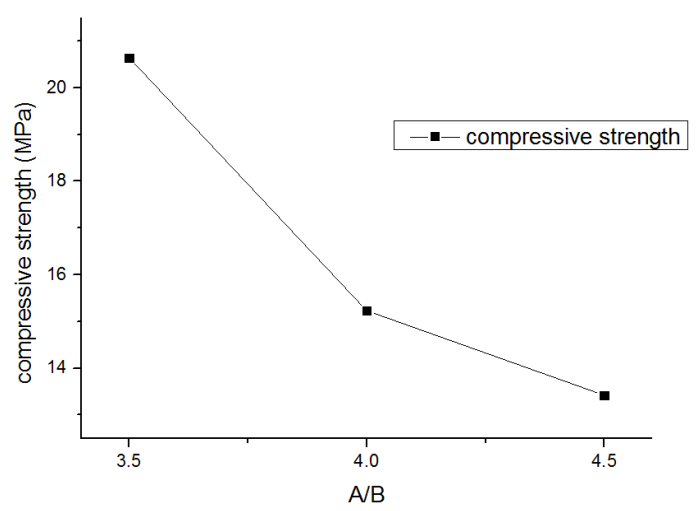

Fig. 3 The relationship between compressive strength and aggregate binder ratio

As shown in Fig.3, the compressive strength of the pervious concrete increases as the aggregate binder ratio decreases. It is well recognized that pervious concrete can be destroyed in the following two main forms: destruction among the aggregate points or the deconstruction of aggregate. For the identical aggregate, the porosity of pervious concrete decreases with the decreases of the aggregate binder ratio, and the plaster cover the aggregate also increases. Therefor, the compressive strength of pervious concrete are increased means the strength of aggregate points are increased.

As the aggregate binder ratio was reduced first from 4.5 to 4.0 and then to 3.5 , the compressive strength increased $13.5 \%$ and $35.5 \%$, respectively, the value of $35.5 \%$ is 2.62 times as much as $13.5 \%$. This can be explained as follows: First, the binder thickness over the recycled aggregate increases with the decrease of the aggregate binder ratio, the compensation effect of the binder to the aggregate becomes more pronounced. Second, the specific surface area of the granule reduces gradually as the aggregate is covered by the binder. When the content of the binder increases in an equal increment, the increment of the binder thickness on the surface of the recycled aggregate increases. As the aggregate binder ratio was reduced first from 4.5 to 4.0 , and then to 3.5 , the porosity was reduced $4.9 \%$ and $11.9 \%$, respectively, and the ratio of these two values is 2.42 .

\section{The effects of the aggregate binder ratio on the flexural strength}

The relationship between flexural strength and aggregate binder ratio are shown in Fig.4.

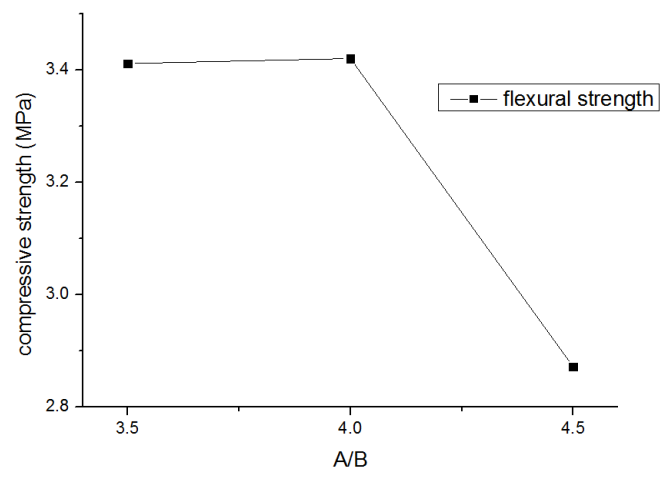

Fig.4 The relationship between flexural strength and aggregate binder ratio

The variation of the flexural strength as a function of the aggregate binder ration of recycled aggregate pervious concrete is presented in Fig.4. As indicated in Fig. 4, the flexural strength is basically identical when the aggregate binder ratio is 3.5 or 4 , but it decreases $15.9 \%$ when the 
aggregate binder ratio is 4.5. The higher the aggregate binder ratio, the lower the filling rate of binder. When the aggregate binder ratio is 4.5 , the flexural failure occurs mainly in the joints among the aggregates. When the aggregate binder ratio reduces to 4 , the binder on the surface of the aggregate is thicker and thus the flexural strength is increased. However, the recycled aggregate itself has micro crack damage in the process of production, when the aggregate binder ratio reduces from 4 to 3.5, the increase of binder is not enough to compensate for the damage of aggregate itself to the flexural strength of pervious concrete. Therefore, the flexural strength of the pervious concrete increases first and then becomes flat with the decrease of aggregate binder ratio.

\section{The effects of the water cement ratio on the compressive strength}

The effects of the water cement ratio on the compressive strength of recycled aggregate pervious concrete and binder are shown in Fig.5(a)and Fig.5(b)

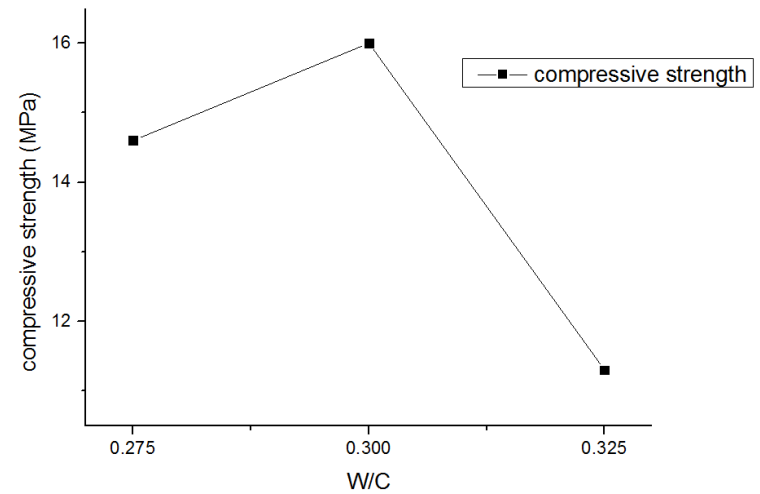

(a)

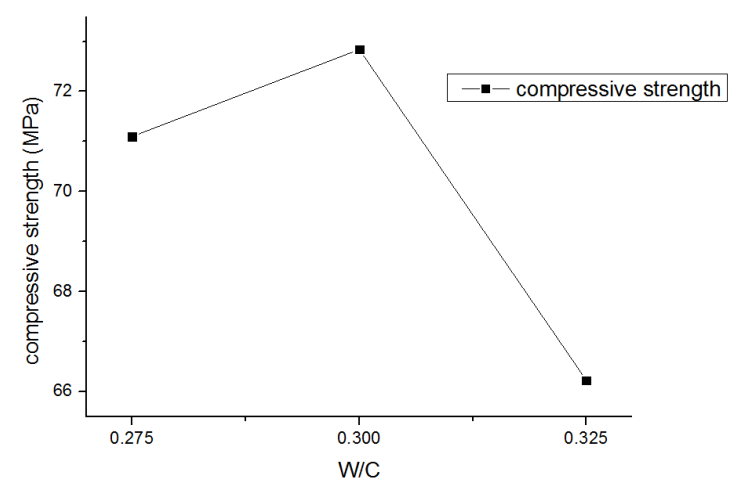

(b)

Fig.5 The relationship between compressive strength and water cement ratio

(a- The relationship between compressive strength and water cement ratio of the recycled aggregate pervious concrete b- The relationship between compressive strength and water cement ratio of the binder)

From Fig.5 (a), it can be seen that the compressive strength of the pervious concrete initially increases and subsequently decreases with the increase of water cement ratio. This is because the binder thickness over the aggregate is the same when the aggregate binder ratio is equal, and the compressive strength of pervious concrete is mainly influenced by the strength of binder, which is intimately related to the water cement ratio. It was found that the strength of cement initially increases and then decreases with the increase of water cement ratio (as shown in Fig.5 (b))

\section{The effects of the water cement ratio on the flexural strength}

The influences of water cement ratio on the flexural strength of the concrete and binder are shown in Fig.6(a)and Fig.6(b)

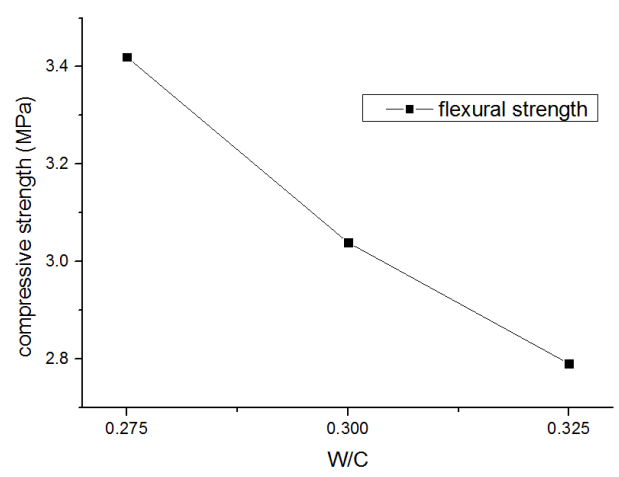

(a)

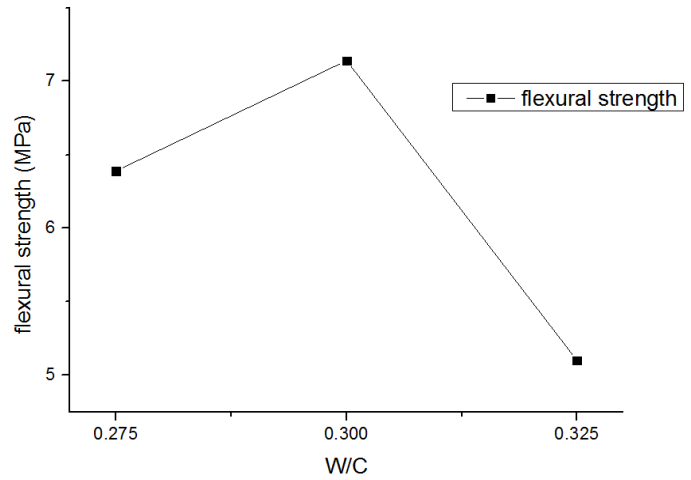

(b)

Fig.6 The relationship between flexural strength and water cement ratio

(a- The relationship between flexural strength and water cement ratio of the recycled aggregate pervious concrete b- The relationship between flexural strength and water cement ratio of the binder)

As you can see from Fig.6 (a), the flexural strength of the pervious concrete decreases with the increase of water cement ratio, which is different from the relationship between flexural strength and water cement ratio of the binder (as shown in Fig.6 (b)). 
This is because the flexural strength of the pervious concrete is low, when the water cement ratio is 0.3 , The influences of unevenness and the defects of recycled aggregate itself on the flexural strength has more influence than the compensation effect of binder on flexural strength of the pervious concrete

\section{Conclusions}

1. The compressive strength of recycled aggregate pervious concrete increases with the decrease of the aggregate binder ratio and the range of increase gradually increased, moreover, the flexural strength increases first and then becomes flat with diminish of the aggregate binder ratio.

When the aggregate binder ratio is lower than 4 , the increase of the binder content can compensate the influences of recycled aggregate on the compressive strength of pervious concrete, but it is not enough to compensate for the influences of the flexural strength.

2. The compressive strength of recycled aggregate pervious concrete and binder initially increase and subsequently decrease with the increase of water cement ratio.

3. Subjected to the unevenness and crack defects of recycled aggregate, the flexural strength of recycled aggregate pervious concrete and binder shows different variation trends with the increase of the water cement ratio.

\section{Acknowledgements}

This work was financially supported by China State Construction Engineering Co. LTD (CSCEC-2016-Z-28, CSCEC-2017-Z-3).

\section{References}

[1] Peijiang Fu. etc. Experim ental study on strength and shrinkage properties of pervious concrete [J]. concrete [In Chinese],2009(8),pp.18-21

[2]Yangang Zhang. etc. Discussion on influence factors of strength of pervious concrete used cinder or gravel as aggregate [C]. 2013 Symposium on concrete and cement products [In Chinese],2013(7),pp.309-313

[3]Yunxing Shi.etc. Porous Concrete and Pervious Pavement[M].China: China Architecture \& Building Press, 2016

[4]Yunxing Shi.etc. Properties of pervious concrete and its paving construction[C]. The 6th International Conference of Asian Concrete Federation, 2014(9),pp.710-715 